\title{
Inhaled micronised gentamicin powder: a new delivery system
}

\author{
J M Goldman, S M Bayston, S O’Connor, R E Meigh
}

\begin{abstract}
Forty patients undergoing routine bronchoscopy were randomised to receive inhaled micronised gentamicin powder (180 mg) or nebulised gentamicin solution (160 mg) one hour before the procedure. Similar levels of gentamicin were detected in bronchoalveolar lavage fluid in the two groups (micronised powder $(n=20) 9.3$ (SD 9.3) $\mathrm{mg} / 1$, nebulised solution $(n=20) 8 \cdot 0(7 \cdot 8) \mathrm{mg} / 1)$. The micronised gentamicin powder preparation caused cough in half the patients but this did not stop their receiving a full dose. Dry powder gentamicin may be a convenient formulation for long term inhaled treatment if the problem of cough can be overcome.
\end{abstract}

In patients with cystic fibrosis colonised with pseudomonas regular administration of nebulised gentamicin and carbenicillin improves lung function and reduces the frequency of hospital admission. ${ }^{12}$ Although inhaled antibiotics are now commonly used in patients with cystic fibrosis and bronchiectasis, nebulising antibiotics in the home is time consuming, limits mobility, and leads to deposition of drug in the local environment. We have developed a micronised powder formulation of gentamicin sulphate that can be inhaled via a Rotahaler dry powder inhaler (Allen and Hanbury). It has the potential advantages of being quick and convenient to use and clean. The aim of this study was to determine whether gentamicin given by Rotahaler could reach concentrations in the airways similar to those of optimally nebulised gentamicin.

\footnotetext{
Department of Respiratory Medicine J M Goldman $S$ O'Connor

Department of Pharmacy $S$ M Bayston

Department of Microbiology R E Meigh

Castle Hill Hospital, Cottingham, North Humberside

Address for reprint requests: Dr J M Goldman, Lung Function Unit, Killingbeck Hospital, York Road, Leeds LS14 6UQ

Accepted 16 August 1990
}

\section{Methods}

We studied 40 patients undergoing routine fibreoptic bronchoscopy. All had a forced expiratory volume in one second $\left(\mathrm{FEV}_{1}\right)$ above 1.0 litre, no current infection, and no previous reaction to lactose or aminoglycosides. Patients were randomised to receive gentamicin sulphate $160 \mathrm{mg}$ in $4 \mathrm{ml}$ normal saline from a Turret nebuliser driven by air at $10 \mathrm{l} /$ minute to dryness $^{3}$ or micronised gentamicin sulphate powder $180 \mathrm{mg}$ combined with a lactose carrier in six capsules (manufactured in our pharmacy) administered via a Rotahaler. The particle size of the gentamicin powder (Roussel Laboratories Ltd) was: $100 \%$ below $50 \mu \mathrm{m}, 99 \%$ below $20 \mu \mathrm{m}$, and $95 \%$ below $10 \mu \mathrm{m}$. The gen- tamicin and lactose combination was similar in particle size characteristics to commercially available micronised salbutamol powder designed for use with the Rotahaler system. One hour after drug administration venous blood was taken for gentamicin assay and fibreoptic bronchoscopy was performed. After inspection of the bronchial tree $100 \mathrm{ml}$ of warmed normal saline was injected via the bronchoscope wedged into the posterior basal segment of a normal lower lobe. Fluid was aspirated and assayed for gentamicin. Gentamicin concentrations were determined with the EMIT (enzyme multiplied immunoassay technique) assay system (SYVA, Maidenhead) according to the manufacturer's protocol. The lower limit of sensitivity for the assay in our laboratory is $1 \mathrm{mg} / \mathrm{l}$ and the coefficient of variation $5 \%$.

The unpaired Student's $t$ test was used to compare measurements in the two groups, and a standard correlation coefficient to compare gentamicin concentrations with other variables.

\section{Results}

There were 20 patients in each group and the mean age was 61 years (table). The indication for bronchoscopy was an abnormal chest radiograph in 29 , haemoptysis in 10 , and clubbing in one. Bronchoscopy showed normal appearances in 19 patients, a tumour in 12 , a narrowed bronchus in six, inflammation in two, and multiple nodules in one.

There was no significant difference in the bronchoalveolar lavage fluid gentamicin concentration between the two groups (table). The groups were similar in all other characteristics. There was no correlation between gentamicin concentration and lung function,

Comparison of the groups of patients receiving nebulised gentamicin solution and micronised gentamicin powder (mean (SD) values unless otherwise specified)

\begin{tabular}{|c|c|c|}
\hline & $\begin{array}{l}\text { Nebulised } \\
\text { solution } \\
(n=20)\end{array}$ & $\begin{array}{l}\text { Micronised } \\
\text { powder } \\
(n=20)\end{array}$ \\
\hline $\begin{array}{l}\text { Gentamicin concentration in } \\
\text { lavage fluid (mean and } 95 \% \\
\text { confidence limits, } \mathrm{mg} / \mathrm{l} \text { ) } \\
\text { Age (y) } \\
\text { FEV }(\% \text { predicted) } \\
\text { FVC (\% predicted) } \\
\text { Delay before lavage (min) } \\
\text { Lavage fluid volume } \\
\text { aspirated (ml) }\end{array}$ & $\begin{array}{l}9 \cdot 3 \\
4 \cdot 9-13 \cdot 7 \\
64 \cdot 1(12 \cdot 7) \\
69 \cdot 0(18 \cdot 2) \\
78 \cdot 5(15 \cdot 5) \\
71 \cdot 3(9 \cdot 7) \\
71 \cdot 5(9 \cdot 8)\end{array}$ & $\begin{array}{l}8.0 \\
4.4-11 \cdot 6 \\
57 \cdot 7(15 \cdot 8) \\
75 \cdot 3(19 \cdot 4) \\
86.0(17.8) \\
66.5(8.5) \\
72 \cdot 8(16.5)\end{array}$ \\
\hline
\end{tabular}


delay before lavage, or volume of lavage fluid aspirated. Gentamicin was not detected in any blood sample.

Half the patients who inhaled the powder preparation developed cough but this did not preclude administration of the full dose.

\section{Discussion}

We have shown that inhaled micronised gentamicin powder produces gentamicin concentrations in bronchoalveolar lavage fluid similar to those produced by gentamicin solution nebulised by an optimal method. ${ }^{3}$ Inhaling a dry powder preparation is quick, convenient, and clean and may be particularly suitable for patients with cystic fibrosis and bronchiectasis who wish to maintain an independent life style. The major problem with the system was cough and we do not believe that the current formulation would be tolerated on a long term basis. Coughing may have been due to the relatively large volume of powder in each capsule, leading to particle aggregation and deposition on the vocal cords, or to airway sensitivity to the powder. Pos- sible solutions to this problem include pretreatment with an inhaled bronchodilator and a different formulation of the capsules; the latter appears to offer greater promise. Ideally a non-irritant preparation with a full dose in a single capsule is required, and further work on the pharmaceutical aspects of the preparation is in progress. Administration of micronised gentamicin powder can achieve adequate concentrations in the airways and this new delivery system for antibiotics may have therapeutic potential. We wish to thank Tony Arnold, Mike Greenstone, and
Damien McGivern for allowing us to study their patients and Damien McGivern for allowing us to study their patients and the nursing staff at the b
Hospital for their assistance.

1 Hodson ME, Penketh ARL, Batten JC. Aerosol carbenicillin and gentamicin treatment of Pseudomonas aeruginosa infection in patients with cystic fibrosis. Lancet ginosa infection

2 Wall MA, Terry AB, Eisenberg J, McNamara M, Cohen $R$. Inhaled antibiotics in cystic fibrosis. Lance 1983;i:1325.

3 Newman SP, Pellow PGD, Clay MM, Clarke SW. Evaluation of a jet nebuliser for use with gentamicin solution. Thorax 1985;40:671-6. 